\title{
Effects of herbal extract supplementation on growth performance and insulin-like growth factor (IGF)-I system in finishing pigs*
}

\author{
G.M. Liu, Y. Wei, Z.S. Wang, D. Wu, A.G. Zhou ${ }^{1}$ and G.L. Liu \\ Institute of Animal Nutrition, Sichuan Agricultural University, Engineering Research \\ Center of Animal Disease-Resistance Nutrition of China Ministry of Education \\ Yaan, 625014, P.R. China
}

(Received 3 March 2008; revised version 12 August 2008; accepted 27 October 2008)

\begin{abstract}
The study's main objective was to investigate the effects of a specific blend of herbal extracts (HEs) on growth performance, antioxidant status, and components of the insulin-like growth factor (IGF) system in finishing pigs. A total of 16 PIC (Pig Improvement Company) pigs (60.1 $1.2 \mathrm{~kg}$; eight gilts and eight barrows) were randomly assigned to one of the two dietary groups, with four pens/group (per pen: one gilt, one barrow). The pigs were fed with a basal diet containing 0 (control) or $250 \mathrm{mg} \mathrm{HEs} / \mathrm{kg}$ diet for 47 days. The results indicated that herbal extract supplementation led to an increase $(\mathrm{P}<0.05)$ on the average daily gain and serum IGF-I level, and a decrease $(\mathrm{P}<0.05)$ on serum malondialdehyde and feed conversion ratio. However, feed intake was not affected $(\mathrm{P}>0.05)$. IGF-I, insulin receptor mRNA levels (liver, stomach, duodenum, muscle) and IGF-I receptor (IGFIR) mRNA (stomach, duodenum, muscle) were high $(\mathrm{P}<0.05)$, while the level of IGF-IR mRNA was low $(\mathrm{P}<0.05)$ in the liver tissue compared with the control pigs. The results suggest that herbal extract supplementation has an antioxidant capacity, enhance the growth performance and exhibits tissue-specific regulation of IGF-IR mRNA level. In addition, the results also suggest the possible physiological role of the IGF system in controlling the HEs-supported growth of finishing pigs.
\end{abstract}

KEY WORDS: pigs, gain, herbal extracts, malonylodialdehyde, insulin-like growth factor system, gene expression

\footnotetext{
* Supported by the Program for Changjiang Scholars and Innovative Research Team in the University, Project No. IRTO555

${ }^{1}$ Corresponding author: e-mail: Zhouanguo02@yahoo.com.cn
} 


\section{INTRODUCTION}

Extensive use of antibiotics results in residual medication of animal products as well as bacterial antibiotic resistance and tolerance (Hamilton-Miller, 2004). This situation represents a considerable risk to human health. Moreover, domestic animals are frequently exposed to oxidative stress, especially in intensive breeding systems. Oxidative stress through changes in the intracellular environment and generation of free radicals such as superoxide, hydrogen peroxide, hydroxyl free radical, or singlet oxygen can lead to lipid peroxidation, protein damage, and mutations in DNA. Therefore, the development of non-antibiotic additives that are highly efficient, abundant, and have low toxicity and antioxidant capacity is urgent. Many herbal extracts (HEs) have been reported to have immunity, antioxidant capacity, and growth enhancement. They are also seen to have a great potential in practical applications.

Biosun ${ }^{\circledR}$ is a mixture of extracts from five plants, namely, Astragalus membranaceus Bunge (AM), Lycium barbarum L. (LB), Atractylodes macrocephala Koidz (AMK), Shenqu (SQ), and Glycyrrhiza uralensis Fiseh (GU). AM is composed of Astragalus polysaccharide, flavonoids (isoflavone, isoflavan) and astragalosides. LB contains the polysaccharide of Lycium barbarum L. AMK includes polysaccharide of Atractylodes macrocephala Koidz, atractylon and atractylenolide. SQ contains enzymes, vitamin B complex, ergosterol and glycosides. GU includes Glycyrrhizin polysaccharide. Biological actions of AM, LB, AMK, SQ and GU herbal extracts have mostly been studied in humans and rats (Kong, 2007). However, few studies have been conducted to evaluate the effects of a mixture of these HEs on the performance and antioxidative capacity in finishing pigs. Therefore, the objectives of this study were: 1 . to examine the possible effects of HEs on antioxidant status and growth performance in finishing pigs, and 2. to look into HEs on components of the insulin-like growth factor (IGF) system of finishing pigs.

\section{MATERIAL AND METHODS}

\section{Experimental animals and diets}

The experimental protocols used in this study were approved by the Sichuan Agricultural University Institutional Animal Care and Use Committee. A total of 16 PIC (Pig Improvement Company) pigs $(60.1 \pm 1.2 \mathrm{~kg}$; eight gilts and eight barrows) were randomly assigned to one of two dietary groups, with four pens per group (per pen: one gilt and one barrow). Each pen was equipped with a feeder and 
muscle tissues were removed. The samples were quickly frozen in liquid nitrogen and were stored at $-80^{\circ} \mathrm{C}$ until use for RNA analysis.

\section{Measurement of IGF-I in the serum}

The detection of IGF-I concentration was performed by using radioimmunoassay counter equipment (Shanghai He Fu Photoelectric Instrument Co. Ltd., Shanghai, China). Concentration of IGF-I in the serum was determined by using pig IGF-I kit (Diagnostic System Laboratories Inc., Webster, TX, USA), which used purified recombinant pig IGF-I as standard, a first antibody raised in guinea pigs, and a goat anti-guinea pig IgG for the bound/free IGF-I separation. A standard curve was prepared at concentrations from 0 to $1000 \mathrm{ng} / \mathrm{ml}$. All samples were analysed in duplicate. The sensitivity of the assay was $2.02 \mathrm{ng} / \mathrm{ml}$. The intra-assay and inter-assay coefficients of variation were $<6.8 \%$ and $<7.1 \%$, respectively.

\section{Serum malondialdehyde (MDA) detection}

The detection of MDA concentration was performed by using 722 spectrophotometric equipment (Shanghai Precision and Scientific Instrument Co. Ltd., Shanghai, China). MDA as an end product of lipid peroxidation can indicate the rate of oxidative stress. MDA was determined by commercial reagents (Nanjing Jiancheng Bioengineering Institute, Nanjing, China) according to the manufacturer's instructions. Briefly, the serum $(0.1 \mathrm{ml})$ was mixed with $1 \mathrm{ml}$ of 0.6 $\mathrm{mol} / \mathrm{l}$ ice-cold trichloroacetic acid and $4 \mathrm{ml}$ of the thiobarbituric acid reagent. The reaction mixture was heated at $95^{\circ} \mathrm{C}$ for $10 \mathrm{~min}$. After mixing and centrifugation at $2000 \mathrm{~g}$ for $5 \mathrm{~min}$, the upper phase was taken for measurement at $532 \mathrm{~nm}$ with the 722 spectrophotometric equipment.

\section{Total RNA isolation and reverse transcription (RT)}

In the experiment, total RNA was isolated from the samples ( 100 mg) using TRIzol reagent (TaKaRa, Shiga, Japan) according to the manufacturer's protocol. RNA was treated with RNase-free DNase I (TaKaRa, Shiga, Japan) to remove any contaminating DNA. The treated RNA was dissolved in RNA-free water and quantified using Beckman DU800 spectrophotometer (Beckman Counter, Fullerton, CA, USA) at OD260. An RNA aliquat was verified for its integrity by electrophoresis in 1\% agarosis gel stained with goldview (SBS Genetech, Beijing, China). Then $2 \mu \mathrm{g}$ of total RNA was reverse-transcribed in a $40 \mu \mathrm{l}$ reaction mixture according to PrimerScript RT Reagent Kit specifications (TaKaRa, Shiga, Japan). The RT products (cDNA) were stored at $-20^{\circ} \mathrm{C}$ for analysis of IGF-I, IGF-I 
receptor (IGF-IR), and insulin receptor (IR) mRNA levels by real-time polymerase chain reaction (PCR).

Real-time PCR for quantification of IGF-I, IGF-IR, and IR

Real-time quantitative PCR was performed using Bio-Rad iQ5 Optical System (Bio-Rad Laboratories, Hercules, CA, USA) and DNAmo SYBR Green qPCR commercial kits (TaKaRa, Shiga, Japan), in which SYBR Green I was a double-stranded DNA-specific fluorescent dye. $\beta$-actin was used as the housekeeping gene. Sequences of primers used for quantitative real-time PCR analysis are shown in Table 2 . Reactions were performed in a $25 \mu 1$ volume with

Table 2. Sequences of primers used for quantitative real-time PCR analysis

\begin{tabular}{lllc}
\hline Target gene & Primer & \multicolumn{1}{c}{ Oligonucleotide sequences (5'-3') } & Product size (bp) \\
\hline$\beta$-actin & Sense & TGCGGGACATCAAGGAGAAG & 216 \\
& Antisense & AGTTGAAGGTGGTCTCGTGG & \\
IGF-I & Sense & GTAACCATGAGGCTGAGAAG & 254 \\
& Antisense & AACACAGGTTCCGTCCATGA & \\
IGF-IR & Sense & GCTGAACAGGCTCAACCC & \multirow{2}{*}{ ( } \\
& Antisense & CGACGCCTTCATAAACCA & \\
IR & Sense & AAACGCCAGGGACATCGTCAAGG & 238 \\
& Antisense & CCGCAGGGAACGCAGGTAACTCT & \\
\hline
\end{tabular}

IGF-I - insulin-like growth factor; IGF-IR - IGF-I receptor; IR - insulin receptor

$12.5 \mu 1$ SYBR Premix Ex Taq (TaKaRa, Shiga, Japan), $2.0 \mu 1$ of cDNA, 9.5 $\mu 1$ double distilled $\mathrm{H}_{2} \mathrm{O}$, and $0.5 \mu 1$ of primer pairs $(10 \mu \mathrm{mol} / 1$ forward and 10 $\mu \mathrm{mol} / 1$ reverse). Cycling conditions were $95^{\circ} \mathrm{C}$ for $10 \mathrm{~s}$; by 45 cycles $\left(95^{\circ} \mathrm{C}\right.$ for $5 \mathrm{~s}$, with different annealing temperatures for different target gene for $30 \mathrm{~s}$ ); followed by $95^{\circ} \mathrm{C}$ for $1 \mathrm{~min}$ and $55^{\circ} \mathrm{C}$ for $1 \mathrm{~min}$. The melting curve program was $55-95^{\circ} \mathrm{C}$ with a heating rate of $0.5^{\circ} \mathrm{C} / 30 \mathrm{~s}$ and a continuous fluorescence measurement. The annealing temperatures for IGF-I, IGF-IR, IR, and $\beta$-actin were 61,60 , 62 , and $61^{\circ} \mathrm{C}$, respectively. To confirm specific amplifications, the PCR products from each primer pair were subjected to a melting curve. The melting curve was determined by holding the reaction at $55^{\circ} \mathrm{C}$ for $30 \mathrm{~s}$ and then heating slowly to $95^{\circ} \mathrm{C}$ with a linear rate of $0.2^{\circ} \mathrm{C} / \mathrm{s}$, while the fluorescence emitted was measured. The $\beta$-actin housekeeping gene was amplified for each sample to verify the presence of cDNA and as an internal control to calculate the relative levels of target gene expression for IGF-I, IGF-IR, and IR using the $2^{-\Delta \Delta C t}$ method (Livak and Schmittgen, 2001). In brief, each experiment was analysed in triplicate and normalized to $\beta$-actin using the following equation: $\Delta \mathrm{Ct}_{\mathrm{GENE}}=\mathrm{Ct}_{\mathrm{GENE}}-\mathrm{Ct}_{\beta \text {-actin }}$. The fold change of the target gene was presented as a value relative to the change in each respective tissue of the 
control pig. The fold change, relative to the control pig, was calculated using the following equation: $2^{(\Delta \Delta C \mathrm{CGENE})}$, where $\Delta \Delta \mathrm{Ct}_{\mathrm{GENE}}=\Delta \mathrm{Ct}_{\mathrm{GENE}}$ of each respective tissue of the control pig- $\Delta \mathrm{Ct}_{\mathrm{GENE}}$ of the tissue of each HEs-supplemented pig. Values represent mean fold change $\pm \mathrm{SEM}$.

\section{Statistical analysis}

The data for all parameters determined were analysed statistically by single factorial variance analysis using the general linear model procedure of SPSS 11.0 software (SPSS Inc., Chicago, Il, USA). The statistical differences between groups were denoted by different letter superscripts. Individual pig was used as the experimental unit for all data except that pen was used as the unit for the average daily gain (ADG), feed intake (ADFI), and feed conversion ratio. Data are expressed as mean \pm SEM. Results were considered significant at $\mathrm{P}<0.05$.

\section{RESULTS}

The average daily gain and serum IGF-I level increased $(\mathrm{P}<0.05)$ by 20.0 and $41.1 \%$, respectively (Table 3 ). However, the serum MDA and feed conversion ratio decreased $(\mathrm{P}<0.05)$ by 35.1 and $11.8 \%$, respectively (Table 3$)$.

Table 3. Effects of herbal extract supplementation on average daily gain (ADG), feed intake (ADFI), feed conversion ratio and serum malondialdehyde (MDA) and insulin-like growth factor (IGF)-I levels of finishing pigs ${ }^{1}$

\begin{tabular}{lcccc}
\hline Item & Control & $\begin{array}{c}\text { Herbal } \\
\text { extract }\end{array}$ & SEM & P \\
\hline ADG, g/d & 644 & 773 & 24 & 0.024 \\
ADFI, kg/d & 2.34 & 2.49 & 0.16 & 0.012 \\
Feed conversion ratio, g feed/g gain & 3.65 & 3.22 & 0.05 & 0.007 \\
Serum IGF-I ${ }^{2}, \mu \mathrm{g} / \mathrm{l}$ & 10.16 & 14.34 & 0.76 & 0.044 \\
Serum $_{\text {MDA }}^{2}, \mathrm{nmol} / \mathrm{l}$ & 7.67 & 4.98 & 0.78 & 0.049 \\
\hline
\end{tabular}

${ }^{1}$ each treatment had eight finishing pigs (four gilts and four barrows) and four replicates $(n=4)$

${ }^{2}$ each treatment had four finishing pigs (two gilts and two barrows) $(\mathrm{n}=4)$

differences were considered significant at $\mathrm{P}<0.05$

Compared with the control pigs, IGF-I and IR mRNA levels within liver, stomach, duodenum, or muscle tissue were high $(\mathrm{P}<0.05)$, respectively (Figures $1 \mathrm{~A}$ and $1 \mathrm{C})$. Herbal extract supplementation increased $(\mathrm{P}<0.05)$ the IGF-IR mRNA levels within the stomach, duodenum, or muscle tissue (by 831, 496 and $442 \%$, respectively), but reduced $(\mathrm{P}<0.05$ ) IGF-IR within the liver tissue (by $60 \%$ ) (Figure 1B). 
A

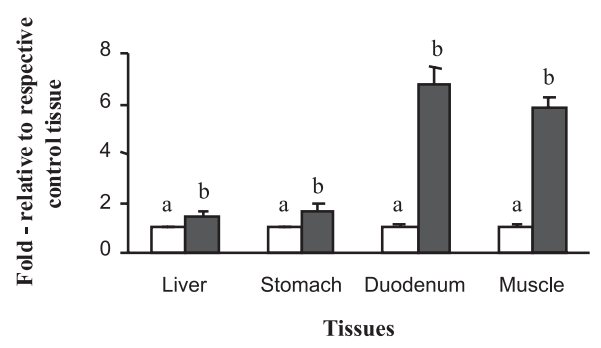

C

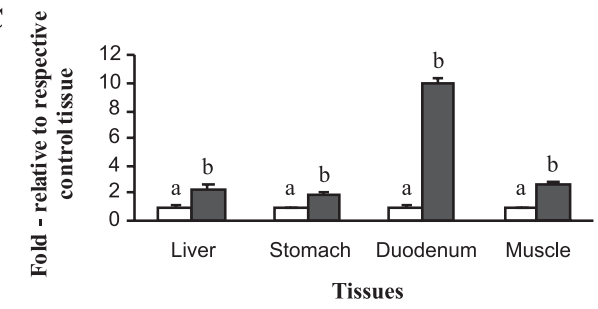

B

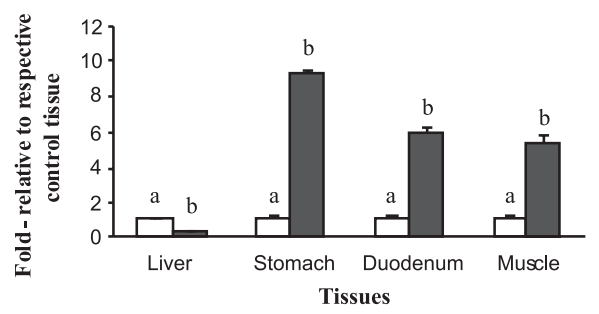

$\square$ Control

口 Herbal extract

Figure 1. Effects of dietary herbal extract supplementation on insulin-like growth factor (IGF)-I (A), IGF-I receptor (B), insulin receptor (C) mRNA levels in several tissues of finishing pigs. The fold change of IGF-I, IGF-I receptor, or insulin receptor mRNA level was presented as a value relative to the change in each respective tissue of the control pig. Data were normalized to $\beta$-actin

\section{DISCUSSION}

HEs can improve growth performance of finishing pigs. Moreover, HEs can increase nutrient digestibility and improve carcass characteristics and meat quality of finishing pigs (data not shown). Thus, HEs may be a candidate of good feed additive. In this study, the molecular mechanism of growth promotion was mainly emphasized.

It is well known that an improvement in the pig's growth performance can be achieved through enhancing their growth rate, which is affected by different factors such as feed abundance and quality. No previous data are available on the effect of different blends of HEs used in the present study on animal growth performance. However, some studies have been conducted on plants containing Astragalus polysaccharide, Atractylodes macrocephala Koidz polysaccharide, and Glycyrrhizin polysaccharide, which are also present in AM, AMK and GU, respectively. The growth rate of weaned piglets and chickens has been reported to improve when supplemented by Astragalus polysaccharide (Li et al., 2007). The polysaccharide of Atractylodes macrocephala Koidz is known to increase the growth rate of weaned piglets and ducks (Peng, 2006). Specifically, the 
development of chickens is enhanced by adding Glycyrrhizin polysaccharide in their feed supplement (Wang et al., 2004). In the current study, daily gain was increased while feed conversion ratio was decreased with herbal extract supplementation. Thus, the growth rate was a result of HEs supplementation. Interestingly, the effects of these on growth rate are regulated by the pigs' endocrine system. The somatotrophic axis, which includes IGF-I, IGF-IR, and IGF-binding proteins that are found in animals, is believed to play a key role in regulating growth. However, there is lack of data about the possible physiological role of IGF in controlling the HEs-supported growth of finishing pigs. Therefore, we hypothesized that HEs can affect insulin-like growth factor (IGF)-I secretion and IGF-I, IGF-I receptor (IGF-IR), and insulin receptor (IR). In this study, serum IGF-I concentration was enhanced by supplying herbal extracts. IGF-I is a potent growth factor that has been associated with a wide range of anabolic processes. It has been shown to stimulate proliferation, differentiation, and other cellular functions in different tissues. The liver is the organ that circulates IGF-I in the body. It has been reported that the decrease in serum IGF-I, which is caused by nutritional changes, is accompanied by a decrease in the levels of hepatic IGF-I mRNA in rats, quail and chickens. However, substantive information on the effects of dietary herbal extract supplementation on IGF-I gene expression in pigs is not available. In this study, HEs increased IGF-I mRNA levels within the liver, stomach, duodenum, or muscle tissue. The increase in IGF-I mRNA levels of several tissues may enhance IGF-I secretion and promote tissue growth and development in the local environment. This is in agreement with the study that HEs can increase protein accretion (data not shown) and thus improve the growth rate of finishing pigs.

The biological actions of IGF-I are controlled mainly through its specific cellsurface receptor, IGF-IR, and in part through IR. Thus, it is worth examining how dietary herbal extract supplementation affects the expression of IGF-IR and IR mRNAs in several tissues. IGF-IR mRNA levels by herbal extract supplementation were high within stomach, duodenum, or muscle tissue, but IGF-IR level was not affected within the liver. This result suggests that herbal extract supplementation has a tissue-specific regulatory mechanism of IGF-IR. HEs-related changes in IGF-IR and IR may be secondary to changes in tissue IGF-I expression, and they occur to either increase or decrease IGF-I activity in the tissues. In herbal extract supplementation, IGF-IR levels in the stomach, duodenum, and muscle have a positive response to IGF-I. It is well established from in vitro systems that the IGF system, which acts through the IGF-IR, has acute anabolic effects on metabolism as well as long-term effects on cell replication and differentiation (Jones and Clemmons, 1995). The data suggest that the IGF system may play an important role in managing the effect of HEs on the stomach, duodenum 
and muscle development of the finishing pigs. Herbal extract supplementation increased the IGF-I mRNA level and lowered the IGF-IR level within the liver tissue. This reaction demonstrates that the effect of herbal extract supplementation on IGF-I and IGF-IR levels is quantitatively different within the tissue, suggesting that the regulation of IGF-I and IGF-IR levels' gene expression by herbal extract supplementation is inconsistent.

Unfortunately, no previous data are available on the effect of the HEs blend used in the current study on the antioxidative status of finishing pigs. The important bioactive antioxidative compounds of the mixture were Astragalus polysaccharides, Lycium barbarum polysaccharides, and flavonoids. Previous studies have documented the effects of AM against oxidation (Ko et al., 2005), LB against oxidation (Luo et al., 2004), AMK against oxidation (Huang, 2005) and GU against oxidation (Zheng and Cheng, 2006). In this study, herbal extract supplementation was found to significantly lower the MDA concentration. This suggests that HEs have an antioxidant capacity and can protect the animal body from free radicals. In addition, it also implies that HEs may be used in reducing animals' stress level.

\section{CONCLUSIONS}

The results presented clearly suggest that herbal extract supplementation has an antioxidant capacity, can enhance growth performance and influence tissuespecific IGF-IR mRNA level. In addition, the results also suggest the possible physiological role of the IGF system in managing the HEs-supported growth of finishing pigs. However, the antioxidant mechanism of HEs from molecular level in finishing pigs should be considered in future studies.

\section{REFERENCES}

Hamilton-Miller J.M.T., 2004. Antibiotic resistance from two perspectives: man and microbe. Int. J. Antimicrob. Agents 23, 209-212

Huang G.P., He J.F., Chen Z.H., 2005. The influence of decoction of Ephedra, Baikal skullcap root, Astragalus root and Bighead Atractylodes Rhizome to immunologic function of children with RRI (in Chinese). U. S. Chin. Health Hygiene J. 8, 81-82

Jones J.I., Clemmons D.R., 1995. Insulin-like growth factors and their binding proteins: biological actions. Endocrine Rev. 16, 3-34

Ko J.K.S., Lain F.Y.L., Cheung A.P.L., 2005. Amelioration of experimental colitis by Astragalus membranaceus through antioxidation and inhibition of adhesion molecule synthesis. World J. Gastroenterol. 11, 5787-5794 
Kong L.M., 2007. Immunological regulating effect of the Astragalus membranaceus Bunge (in Chinese). Inner Mongolia Med. J. 39, 73-74

Li T.Z., 2007. Effects of Astragalus polysaccharide on growth performance in weaning pigs. Chin. Feeds 12, 36-38

Livak K.J., Schmittgen T.D., 2001. Analysis of relative gene expression data using real-time quantitative PCR and the $2^{-\Delta \Delta C T}$ method. Methods $25,402-428$

Luo Q., Cai Y., Yan J., 2004. Hypoglycemic and hypolipidemic effects and antioxidant activity of fruit extracts from Lycium barbarum. Life Sci. 76, 137-149

NRC, 1998. Nutrient Requirements of Swine. 10 ${ }^{\text {th }}$ Edition. National Academy Press. Washington, DC

Peng H.Z., 2006. Study on effects of crude polysaccharide of Atractylodes macrocephala Koidz on growth and immune function for weaned piglets (in Chinese). Master's Thesis. Hunan Agricultural University, Hunan (China)

Wang L.R., Zhang H.T., Liu B.G., Dong Y.J., Wang C.M., Wang Y.R., Shi M., Zhang Y.L., 2004. Extraction of Glycyrrhizin polysaccharide and its effects on growth performance of broilers. Chin. Feeds Industry 25, 44-45

Zheng M.C., Chen H., 2006. Study on the antioxidant activity of Liquorice ethanolic extract (in Chinese). Acad. Periodical Farm Prod. Process. 9, 67-69 